\title{
Biocompatible Films of Calcium Alginate Inactivate Enveloped Viruses such as SARS-CoV-2
}

\author{
Alba Cano-Vicent ${ }^{1}$, Rina Hashimoto ${ }^{2}$, Kazuo Takayama 2,* and Ángel Serrano-Aroca 1,*
}

1 Biomaterials and Bioengineering Lab, Centro de Investigación Traslacional San Alberto Magno, Universidad Católica de Valencia San Vicente Mártir, c/Guillem de Castro 94, Valencia 46001, Spain.; alba.cano@mail.ucv.es; angel.serrano@ucv.es

2 Center for iPS Cell Research and Application (CiRA), Kyoto University, Kyoto 606-8507, Japan.; rina.hashimoto@cira.kyoto-u.ac.jp; kazuo.takayama@cira.kyoto-u.ac.jp

* Correspondence: kazuo.takayama@cira.kyoto-u.ac.jp (K.T.) and angel.serrano@ucv.es (A.SA.)

\begin{abstract}
The current pandemic is urgently demanding to discover alternative materials capable of inactivate the severe acute respiratory syndrome coronavirus 2 (SARS-CoV-2) that causes the coronavirus 2019 (COVID-19) disease. Calcium alginate is a crosslinked hydrophilic biopolymer with an immense range of biomedical applications due to its excellent chemical, physical and biological properties. In this study, the cytotoxicity and antiviral activity of calcium alginate in the form of films were studied. The results showed that these films are biocompatible in human keratinocytes and are capable of inactivating enveloped viruses such as bacteriophage phi 6 with a 1.43-log reduction (94.92\% viral inactivation) and SARS-CoV-2 Delta variant with a 1.64-log reduction (96.94\% viral inactivation) in virus titers. The antiviral activity of these calcium alginate films can be attributed to its negative charge density that may bind to viral envelopes inactivating membrane receptors.
\end{abstract}

Keywords: Calcium alginate; SARS-CoV-2; bacteriophage; phi 6; biomaterials; films; hydrogels

\section{Introduction}

The COVID-19 pandemic has forced material engineers to develop and search for alternative materials capable of inactivating SARS-CoV-2 [1-8]. In this regard, sodium alginate (SA) has shown antiviral activity against several types of viruses [9] and possess excellent chemical, physical and biological properties that render this biopolymer very useful for an immense range of industrial applications [10-17]. This carbohydrate polymer presents a linear structure of (1-4)-linked $\beta$-D-mannuronic acid (M) blocks and $\alpha$-L-guluronic acid (G) blocks, which are arranged in a block wise fashion with $\mathrm{M}$ and $\mathrm{G}$ blocks in different ratios and sequences depending on the type of alginate [18-20]. This hydrophilic material is biodegradable, biocompatible, non-toxic, economic in comparison with other biopolymers and renewable because it can be produced from brown algae or microbial culture sources[21]. SA is a water-soluble polymer that can be crosslinked with salts containing divalent cations such as calcium chloride to form hydrogels, that is, polymer gels that can absorb large amounts of water without being dissolved [22]. The gelation process occurs when divalent cations of $\mathrm{Ca}^{2+}$ interact with $\mathrm{G}$ blocks according to the egg-box model buckled structure[23]. The antiviral activity of SA has shown to increase with increasing the amount of $\mathrm{G}$ blocks presents in the backbone polymer structure [24]. However, the antiviral activity of calcium alginate has been hardly studied [25-27]. Thus, according to the previous antiviral studies perform with SA [9], we hypothesize here that calcium alginate films will be able to inactivate enveloped viruses such as SARS-CoV-2 Delta variant and bacteriophage phi 6 . The bacteriophage phi 6 is often used as surrogate of SARS-CoV-2 [28] due to the fact that it is an enveloped virus that can be handle in safety conditions [29]. The pathogenic SARS-CoV-2 Delta variant and the new variants that are emerging, such as omicron sub-lineage BA.2, are a great risk to global public health [30]. 
The SARS-CoV-2 Delta variant is highly transmissible and possesses mutations that may partially confer immune escape [31]. In fact, outbreak investigations suggested that vaccinated people can spread SARS-CoV-2 Delta in a highly vaccinated country $[32,33]$. The toxicological aspects of the synthesized calcium alginate films were analyzed in human keratinocytes $\mathrm{HaCaT}$ cells.

\section{Materials and Methods}

\subsection{Materials}

Alginic acid sodium salt (Panreac AppliChem, Darmstadt, Germany) was previously characterized [34]: number average molecular mass $\left(\mathrm{M}_{\mathrm{n}}\right)=170.7 \pm 3.1 \mathrm{kDa}$; average molecular mass $\left(\mathrm{M}_{\mathrm{w}}\right)=379.5 \pm 9.5 \mathrm{kDa}$; polydispersity $\left(\mathrm{M}_{\mathrm{w}} / \mathrm{M}_{\mathrm{n}}\right)=2.22 \pm 0.08$; distribution of $\mathrm{G}$ and $\mathrm{M}$ blocks as $\mathrm{F}_{\mathrm{G}}=0.427, \mathrm{~F}_{\mathrm{M}}=0.573$, or $\mathrm{M} / \mathrm{G}$ ratio of $1.34, \mathrm{~F}_{\mathrm{GG}}=0.270$ and $\mathrm{F}_{\mathrm{GGG}}=0.234$. $\mathrm{CaCl}_{2}$ (anhydrous, granular, $\leq 7.0 \mathrm{~mm}, \geq 93.0 \%$ ) was purchased from Sigma-Aldrich (Saint Louis, MO, USA).

\subsection{Film preparation}

$0.25 \mathrm{~g}$ of SA was dissolved in $30 \mathrm{~mL}$ of distilled water by magnetic stirring at $24 \pm 0.5$ ${ }^{\circ} \mathrm{C}$ for $1 \mathrm{~h}$. This mixture was poured into a circular mold and was dried to form films by solvent evaporation. Thus, the mold was left at room temperature $\left(24 \pm 0.5^{\circ} \mathrm{C}\right)$ under an extraction hood for $24 \mathrm{~h}$, followed by $48 \mathrm{~h}$ at $37^{\circ} \mathrm{C}$ in an oven. After that, the films were crosslinked by immersion for $1 \mathrm{~h}$ in a crosslinking solution prepared by dissolving $5 \mathrm{~g}$ of calcium chloride in $500 \mathrm{~mL}$ of distilled water under magnetic stirring for 15 minutes at 24 $\pm 0.5^{\circ} \mathrm{C}$. After crosslinking the film, it was washed in distilled water three times to ensure complete removal of calcium chloride residues and left to dry for $24 \mathrm{~h}$ at room temperature, followed by $48 \mathrm{~h}$ at $37^{\circ} \mathrm{C}$. The films were cut into disk specimens of $10 \mathrm{~mm}$ diameter and sterilized by ultraviolet radiation $1 \mathrm{~h}$ per side. This sample is hereafter referred to as AlgCa.

\subsection{Toxicological study}

The films were introduced in a six-well plate using Dulbecco's Modified Eagle's Medium (DMEM, Biowest SAS, France) without Fetal bovine serum (FBS) to fill the wells up to covering completely the surface area. These cytotoxicity tests were performed using a surface material/volume ration of $3 \mathrm{~cm}^{2} / \mathrm{mL}$ according to the ISO-10993 standard recommendations. The film disks were incubated in humidified 5\% carbon dioxide $/ 95 \%$ air ambient for $72 \mathrm{~h}$ at $37^{\circ} \mathrm{C}$ to produce the extracts. Right after that, the extracts were collected and used for the cytotoxicity tests. The cell line used in the cytotoxicity assays was donated by the Biomedical Research Institute and Hospital La Fe, Valencia, Spain, and consisted of non-tumorigenic immortalized human keratinocyte $\mathrm{HaCaT}$ cells. Cell growth was carried out using DMEM with 10\% FBS, 100 units/mL penicillin (Lonza, Belgium), and $100 \mathrm{mg} / \mathrm{mL}$ streptomycin (HyClone, GE Healthcare Life Sciences), at a temperature of $37^{\circ} \mathrm{C}$ and $5 \%$ carbon dioxide. The cytotoxic effects of the film extract on cell viability were analyzed by the 3-[4,5-dimethylthiazol-2-yl]-2,5-diphenyl tetrazolium bromide (MTT) method. The human keratinocytes were planted at a density of $10^{4}$ cells/well onto a 96-well plate. Incubation of the cells was performed for $24 \mathrm{~h}$ at $37^{\circ} \mathrm{C}$ before replacing the culture medium with $100 \mu \mathrm{L}$ of film extract in each well. A positive control was measured replacing the culture medium with $100 \mu \mathrm{L}$ of the same medium used to produce the film extracts. A negative control was measured replacing the culture medium with $100 \mu \mathrm{L}$ of $1000 \mu \mathrm{M}$ zinc chloride ( $\geq 97.0 \%$, Sigma-Aldrich, Saint Louis, MO, USA) cytotoxic solution [34]. A mass/volume amount of $5 \mathrm{mg} / \mathrm{mL}$ MTT in each well was used to incubate the human cells for $3 \mathrm{~h}$. Finally, the dissolution of the formazan crystals was performed in 100 $\mu \mathrm{L}$ of dimethyl sulfoxide (Sigma-Aldrich, Saint Louis, MO, USA) at $24 \pm 0.5^{\circ} \mathrm{C}$ to measure the absorbance $550 \mathrm{~nm}$ with the help of a microplate reader (Varioskan, Thermo Fisher). 


\subsection{Antiviral test with the bacteriophage phi 6}

Pseudomonas syringae (DSM 21482) and bacteriophage phi 6 (DSM 21518) were purchased from the Leibniz Institute DSMZ-German Collection of Microorganisms and Cell Cultures $\mathrm{GmbH}$ (Braunschweig, Germany). This Gram-negative bacterium was cultured in solid tryptic soy agar (TSA, Liofilchem) and subsequently, in liquid tryptic soy broth (TSB, Liofilchem) at 120 r.p.m. and a temperature of $25^{\circ} \mathrm{C}$. Bacteriophage phi 6 propagation was carried out according to the Leibniz Institute DSMZ-German Collection of Microorganisms and Cell Cultures $\mathrm{GmbH}$ specifications. In these antiviral assays, a bacteriophage suspension volume of $50 \mu \mathrm{L}$ was added in TSB to each AlgCa film disk at a titer of about $1 \times 10^{6}$ plaque-forming units per $\mathrm{mL}(\mathrm{PFU} / \mathrm{mL}$ ) to be incubated for $30 \mathrm{~min}$. The AlgCa disks were individually placed in falcon tubes with a TSB volume of $10 \mathrm{~mL}$ to be sonicated at $25^{\circ} \mathrm{C}$ for $5 \mathrm{~min}$, followed by 1 -min vortexing. After that, serial dilutions were performed from each falcon tube for bacteriophage titration. A bacteriophage dilution volume of $100 \mu \mathrm{L}$ was mixed with a host strain volume of $100 \mu \mathrm{L}$ at $\mathrm{OD}_{600 \mathrm{~nm}}=0.5$. Thus, the bacteriophage infective capacity was studied according to the double-layer assay [35]. A volume of $4 \mathrm{~mL}$ of top agar (TSB $+0.75 \%$ bacteriological agar) from Scharlau (Ferrosa, Barcelona, Spain) with $1 \mathrm{mM}$ calcium chloride and the bacteriophage/bacteria suspension were mixed and poured on TSA plates to be cultured at $25^{\circ} \mathrm{C}$ in a refrigerated incubator for $24 \mathrm{~h}$. The antiviral activity was determined at $30 \mathrm{~min}$ of contact by calculating the bacteriophage titers in $\log (\mathrm{PFU} / \mathrm{mL})$ for comparative analysis with the control sample, that is, a similar bacteriophage suspension volume of $50 \mu \mathrm{L}$ mixed with the bacteria without having been in contact with the AlgCa film disk. The null effect of the sonication/vortexing processes on the infectious activity of the bacteriophage phi 6 and the absence of interference of the residual amounts of the calcium alginate films with the titration procedure were checked to avoid false results. These antiviral assays were performed three times in two different days $(n=6)$ to provide reliable results.

\subsection{Bacteriophage RNA extraction and quantification}

In order to ensure that the viral particles do not remain adhered to the AlgCa films providing false positive results in the antiviral experiments, double-stranded RNA extraction and quantification of the bacteriophage phi 6 were performed before and after being in contact with the calcium alginate films. These tests are very important to ensure that the viruses inactivate after being in contact with the AlgCa films. A volume of $50 \mu \mathrm{L}$ with a bacteriophage concentration of $1 \times 10^{6} \mathrm{PFU} / \mathrm{mL}$ was dispersed on the AlgCa film disks and left to incubate at $25^{\circ} \mathrm{C}$ for $30 \mathrm{~min}$. A volume of $50 \mu \mathrm{L}$ of the same bacteriophage dispersion without having been in contact with the films was left to incubate at $25^{\circ} \mathrm{C}$ for $30 \mathrm{~min}$ (control). After incubation, $10 \mathrm{~mL}$ of TSB were mixed with the samples to perform sonication and vortexing for $5 \mathrm{~min}$ and $45 \mathrm{~s}$, respectively. After that, RNA extraction was carried out using the RNA extraction protocol of Norgen Biotek Corp. (Ontario, Canada) [36]. Thus, viral particle-lysing was performed to produce a transparent mixture. After this first step of the protocol, RNA purification was performed by binding this molecule to the purification column, washing of the purification column, and elution of the RNA for storage at $-70{ }^{\circ} \mathrm{C}$ to avoid degradation. Finally, the amount of RNA was quantified with a nanodrop (Thermo Scientific, Waltham, USA) to express the results in $\mathrm{ng} / \mu \mathrm{L}$. These extractions and quantifications were performed in triplicate to provide reproducible values.

\subsection{Antiviral test with SARS-CoV-2 Delta variant}

The SARS-CoV-2 strain (B.1.617.2, Delta) provided by BEI Resources (NR-55611, $\mathrm{hCoV}-19 / \mathrm{USA} / \mathrm{PHC} 658 / 2021)$ was stored at $-80{ }^{\circ} \mathrm{C}$. Plaque-purification and propagation was performed in TMPRSS2/Vero cells. $500 \mu \mathrm{L}$ of SARS-CoV-2 viral suspension in minimum essential medium (MEM, Sigma-Aldrich) was added to each AlgCa film at $1.0 \times 10^{6}$ median tissue culture infectious dose (TCID50) per film (TCID50/film), and then 
incubated at room temperature for $30 \mathrm{~min}$. $500 \mu \mathrm{L}$ MEM were added to each AlgCa film, and then vortexed for $5 \mathrm{~min}$. Viral titers were measured by the TCID50 assays in a Biosafety Level 3 laboratory at Kyoto University. Thus, TMPRSS2/Vero cells (JCRB1818, JCRB Cell Bank), cultured with MEM supplemented with 5\% FBS and 1\% penicillin/streptomycin, were seeded into 96-well plates (Thermo Fisher Scientific). Serial dilutions 10fold from $10^{-1}$ to $10^{-8}$ were performed to be placed onto the TMPRSS2/Vero cells in triplicate and incubated at $37^{\circ} \mathrm{C}$ for $96 \mathrm{~h}$. Microscopic evaluation of the cytopathic effects and the Reed-Muench method was used to determine TCID50/mL.

\subsection{Statistical analysis}

One-way ANOVA with subsequent Tukey's posthoc test and student's t-test was carried out for multiple and pair comparisons, respectively using the GraphPad Prism 6 software.

\section{Results}

\subsection{Toxicological study}

The percentages of viability of the human keratinocyte cells determined in the cytotoxicity assays are shown in Figure 1.

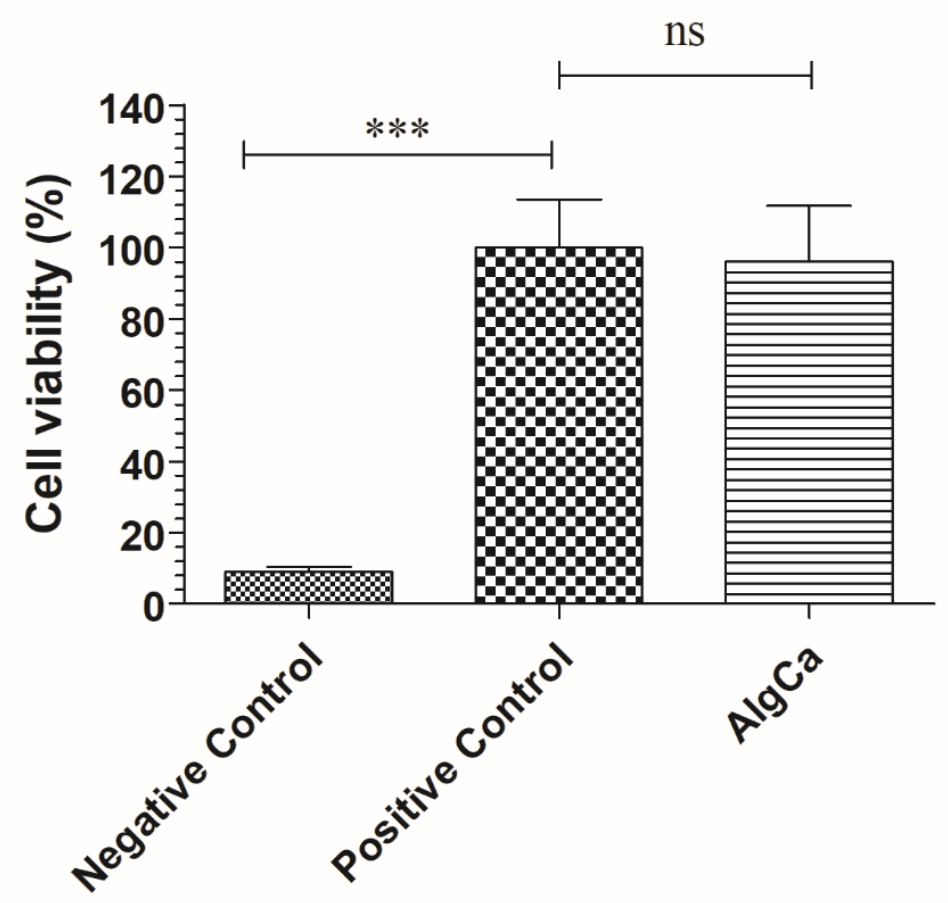

Figure 1. MTT cytotoxicity tests of extracts obtained from the calcium alginate films (AlgCa), positive control (culture medium used to produce the films extracts) and negative control (cytotoxic $1000 \mu \mathrm{M}$ zinc chloride solution) cultured in human keratinocyte $\mathrm{HaCaT}$ cells at $37^{\circ} \mathrm{C}$. ANOVA with subsequent Tukey's posthoc test: ${ }^{* *} p>0.001$; ns, not significant.

The percentages of viability of the human keratinocyte cells determined in the cytotoxicity assays are shown in Figure 1.

The extracts of AlgCa films showed no cytotoxic effects in human keratinocytes. Thus, no statistically significant differences in cell viability (\%) between the extract of the AlgCa film and the positive control was observed. 


\subsection{Antiviral assays with the enveloped bacteriophage phi 6}

Figure 2 shows the antiviral results obtained for bacteriophage phi 6 after being in contact with the AlgCa film in comparison with control.

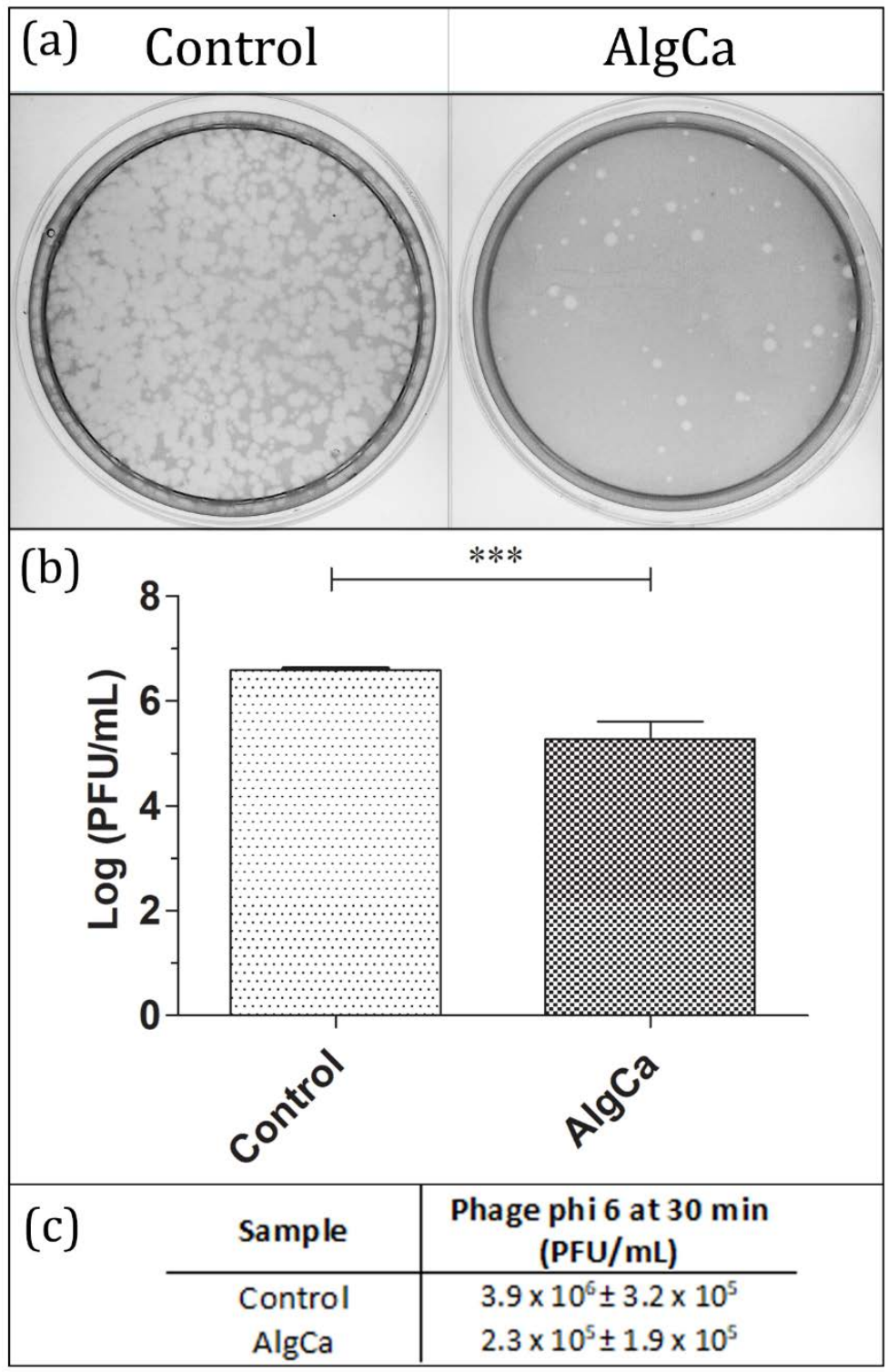

Figure 2. Antiviral activity of calcium alginate against bacteriophage phi 6 determined by the double-layer method: (a) Titration images (undiluted samples) for AlgCa film and control after 30 min of viral contact; (b) Viral inactivation in log (PFU/mL) for AlgCa film and control after $30 \mathrm{~min}$ of viral contact; (c) Reduction of infection titers in plaque-forming units per $\mathrm{mL}(\mathrm{PFU} / \mathrm{mL})$ for AlgCa film and control after $30 \mathrm{~min}$ of viral contact. Student's t-test $\left.{ }^{* * *} p>0.001\right)$.

These results showed that the synthesized calcium alginate film possesses antiviral activity against the bacteriophage phi 6 with 1.43-log viral infectivity reduction $(94.92 \%$ viral inactivation) after $30 \mathrm{~min}$ of viral contact.

\subsection{Bacteriophage RNA extraction and quantification}

Figure 2 shows the antiviral results obtained for bacteriophage phi 6 after being in contact with the AlgCa film in comparison with control. In order to make sure that the bacteriophages phi 6 does not remain attached in the inner part or to surface of the calcium alginate films before the antiviral assays providing false results, RNA extraction and quantification of the bacteriophages were performed before and after being in contact 
with the material. Thus, figure 3a shows similar amounts of bacteriophage RNA with no significant differences before (control) and after being in contact with the AlgCa films.

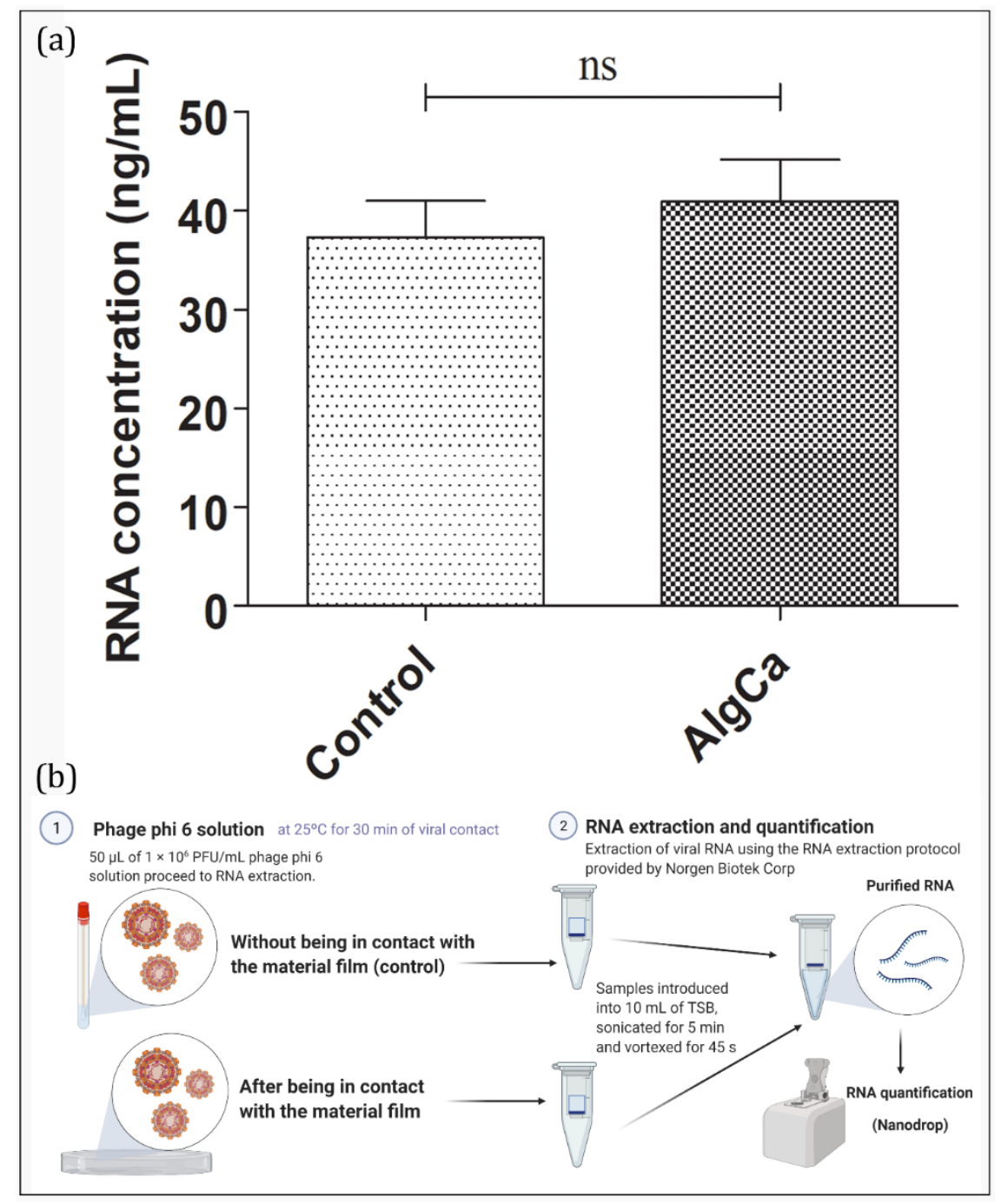

Figure 3. Bacteriophage phi 6 RNA extraction and quantification: (a) Bacteriophage RNA concentration before (control) and after being in contact with the calcium alginate (AlgCa) films for $30 \mathrm{~min}$ expressed in ng/ $\mu \mathrm{L}$. Student's t-test (ns, not significant) ; (b) Schematic representation of the RNA extraction and quantification process protocol to ensure that the viral particles do not remain attached to the material film instead of being inactivated. Created by Ángel Serrano-Aroca with Biorender.com.

Figure $3 b$ shows a scheme that summarizes graphically the bacteriophage RNA extraction and quantification protocol used in these experiments.

\subsection{Antiviral assays with the SARS-CoV-2 Delta variant}

The synthesized calcium alginate films showed also antiviral activity against SARSCoV-2 Delta variant with 1.64-log reduction viral infectivity reduction $(96.94 \%$ viral inactivation) after $30 \mathrm{~min}$ of contact (Figure 4). 


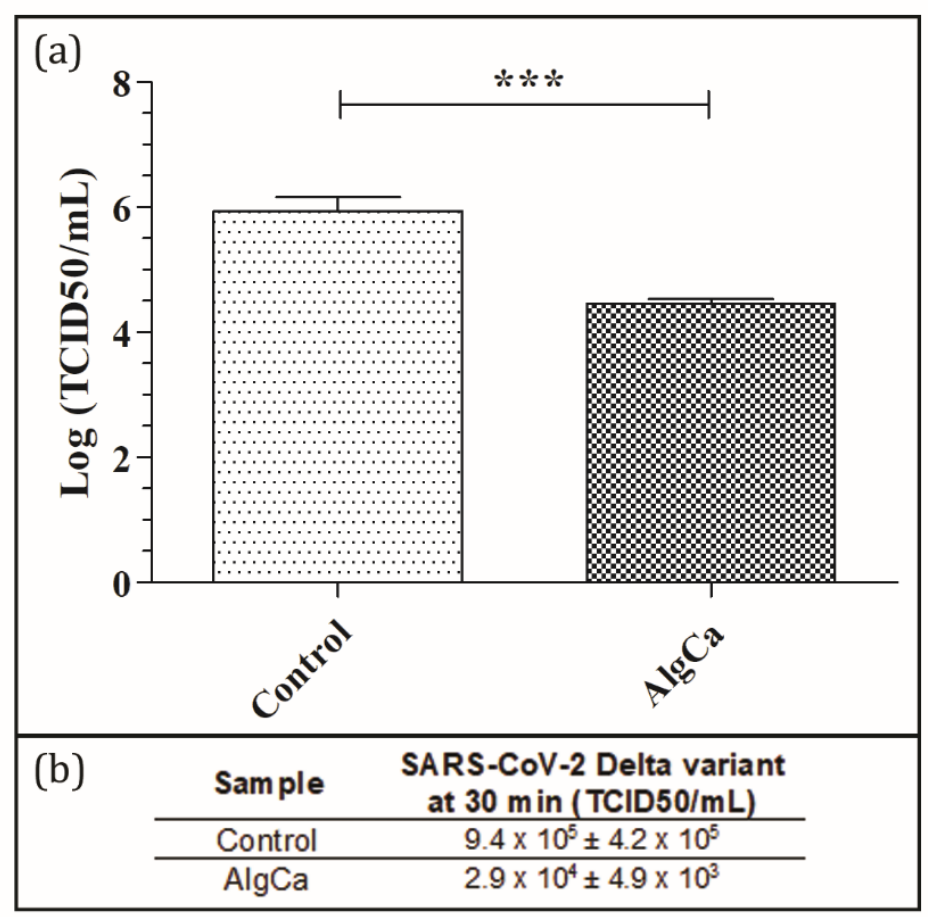

Figure 4. Reduction of infection titers of the SARS-CoV-2 Delta Variant in logarithm of TCID50 per mL (log (TCID50/mL)) (a) and TCID50 per $\mathrm{mL}(\mathrm{b})$. Reduction of infection titers in plaque-forming units per $\mathrm{mL}(\mathrm{PFU} / \mathrm{mL})$ for control and calcium alginate films (AlgCa) at $30 \mathrm{~min}$ of viral contact. ${ }^{* *} p>0.001$. Student's t-test $\left({ }^{* *} p>0.001\right)$.

This reduction was even slightly greater than that observed with bacteriophage phi 6 (Figure 2). The antiviral mechanism of calcium alginate is not clear yet [9]. Thus, a study of alginic acid showed that this anionic biopolymer can bind to a viral envelope, such as that of rabies virus, inactivating its replication [37]. In this context, several studies have attributed the antiviral action of alginate to the aggregation of viral particles in solution $[24,38]$. Moreover, an antiviral study using guluronic acid-rich sodium alginate against Herpes simplex virus type 1 (HSV-1) showed that the antiviral capacity of this biopolymer could be associated to the direct interference with the herpes virion envelop structures associated with cell adsorption[39], in good agreement with other compounds such as monoterpenes derived from essential oils [40] or Pelargonium sidoides extracts [41]. SA with a $\mathrm{M} / \mathrm{G}$ ratio of 1.44 (close to that of the alginic acid sodium salt used in this study, 1.34) showed strong antiviral activity against the enveloped HSV-1 viral particles. However, alginic acid showed only slight inhibition (15-20\%) against the enveloped rubella virus (RV) [25]. Calcium alginate have shown previously negligible antiviral activity $(\leq 0.6-\log$ reduction in virus titers) against the enveloped IFV[26], HCV and SINV[27] RNA viruses and against the non-enveloped double-stranded DNA bacteriophage T4 even after $48 \mathrm{~h}$ of viral contact [42] (0.42-log reduction in virus titers). Therefore, the low or strong antiviral activity of calcium alginate gels could be associated to the total negative charge density of the biopolymer network. The hydrophilic calcium alginate films swell when they are in contact with a viral aqueous solution [21] as depicted in Figure 5a and 5b. 


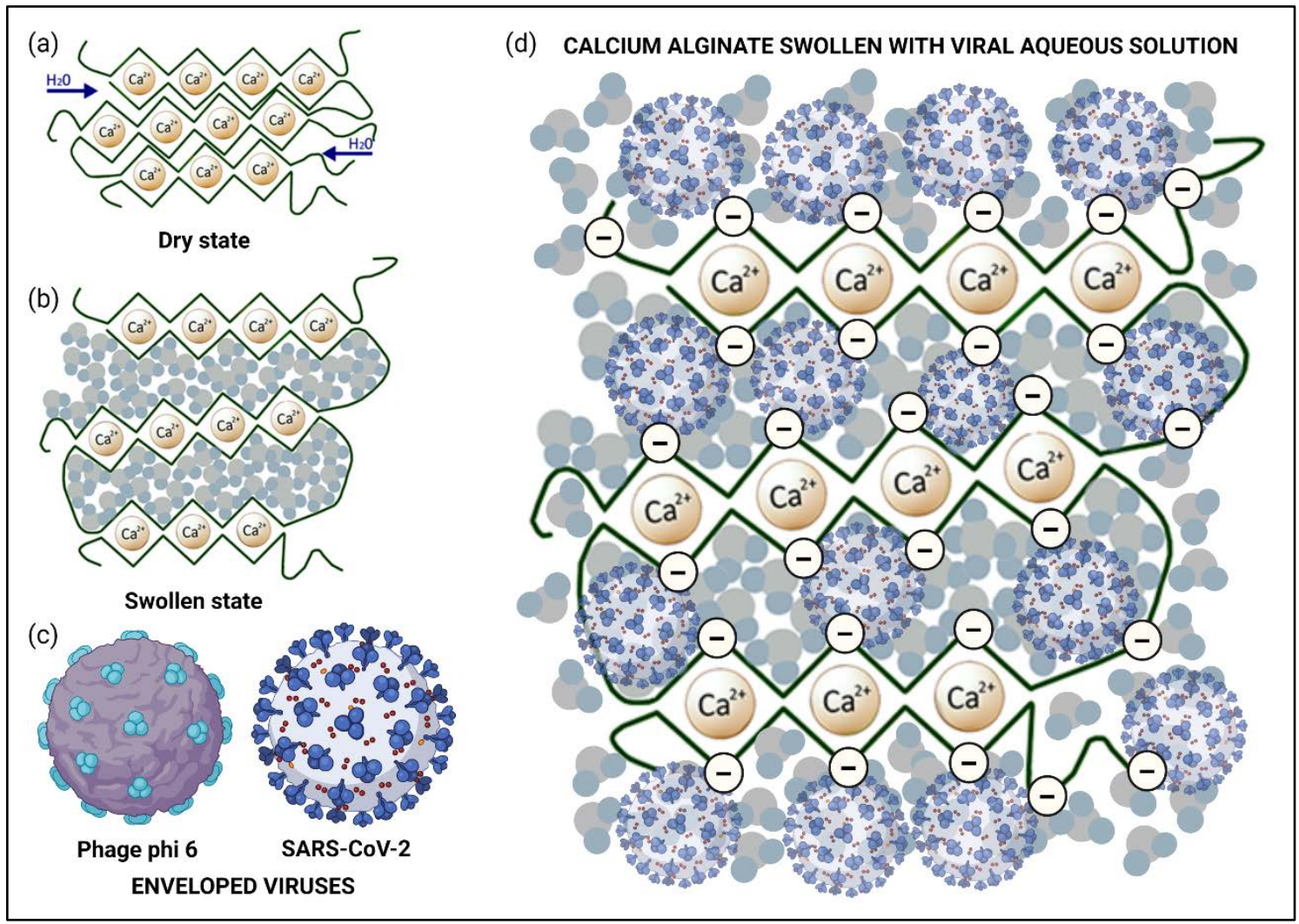

Figure 5. Inactivation mechanism of SARS-CoV-2 Delta variant and bacteriophage phi 6, in the synthesized negatively charged calcium alginate film: (a) calcium alginate structure in dry state according to the egg-box model[21]; (b) calcium alginate in swollen state after being in contact with a viral aqueous solution[21]; (c) enveloped RNA viruses: bacteriophage phi 6 and SARS-CoV-2 viral morphologies; (d) Negatively-charged calcium alginate interfering with SARS-CoV-2 Delta variant in viral aqueous solution. Created by Ángel Serrano-Aroca with Biorender.com.

Thus, the two types of viral particles (Figure 5c) can interact with the negatively charged calcium alginate film surface or porous structure as depicted in Figure 5d. These negative charges can bind to the enveloped RNA viruses inactivating their capacity of infection by interaction with viral structures required for cell adsorption and thus inhibiting viral entry to cells. Therefore, in this study, we have developed biocompatible calcium alginate films with antiviral activity against two enveloped viruses. These results show great promise to combat SARS-CoV-2 and other enveloped viruses in the current and future pandemics.

\section{Conclusions}

Biomaterial films of calcium alginate have shown antiviral activity $(\geq 94.92 \%$ of viral inactivation) against two enveloped viruses, bacteriophage phi 6 (94.92\% viral inactivation) and SARS-CoV-2 Delta variant (96.94\% viral inactivation), and no cytotoxic effects in human keratinocytes for the first time in literature. The antiviral mechanism can be attributed to the negatively charged biopolymer network of calcium alginate that can bind to viral envelopes inactivating its replication. These anti-bacteriophage and anti-SARSCoV-2 biocompatible films of calcium alginate are very promising for a broad range of industrial applications.

Author Contributions: ÁSA conceived the idea of this work; methodology, validation and formal analysis: KT and ÁSA; software: KT and ÁSA; investigation: ACV, RH, KT and ÁSA; resources: KT and ÁSA; data curation: ACV, KT and ÁSA; visualization: KT and ÁSA; writing-original draft preparation: ÁSA; writing-review and editing: ACV, KT and ÁSA; supervision: KT and ÁSA; 
project administration: ÁSA; funding acquisition: KT and ÁSA. All authors read and agreed to the final version of the manuscript.

Funding: This research was funded by Fundación Universidad Católica de Valencia San Vicente Mártir, Grant 2020-231-006UCV (awarded to Á.S.-A), and to the Ministerio de Ciencia e Innovación (PID2020-119333RB-I00/AEI/10.13039/501100011033) (awarded to Á.S.-A) for their financial support. The grants from the Japan Agency for Medical Research and Development (AMED) (20fk0108533h0001) also supported this research. This research was also supported by Joint Usage/Research Center program of Institute for Frontier Life and Medical Sciences Kyoto University.

Data Availability Statement: Not applicable.

Acknowledgments: The authors are grateful to the Fundación Universidad Católica de Valencia San Vicente Mártir, the Ministerio de Ciencia e Innovación, the AMED and the Joint Usage/Research Center program. The authors are thankful to Dr. Yoshio Koyanagi, Dr. Takeshi Noda, and Dr. Kazuya Shimura for the setup and operation of the BSL-3 laboratory at Kyoto University.

Conflicts of Interest: The authors declare no conflict of interest.

\section{References}

1. Park, H.H.; Kim, H.; Lee, H.S.; Seo, E.U.; Kim, J.E.; Lee, J.H.; Mun, Y.H.; Yoo, S.Y.; An, J.; Yun, M.Y.; et al. PEGylated nanoparticle albumin-bound steroidal ginsenoside derivatives ameliorate SARS-CoV-2-mediated hyper-inflammatory responses. Biomaterials 2021, 273, 120827.

2. Gray, L.T.; Raczy, M.M.; Briquez, P.S.; Marchell, T.M.; Alpar, A.T.; Wallace, R.P.; Volpatti, L.R.; Sasso, M.S.; Cao, S.; Nguyen, M.; et al. Generation of potent cellular and humoral immunity against SARS-CoV-2 antigens via conjugation to a polymeric glyco-adjuvant. Biomaterials 2021, 278, 121159.

3. Zhang, H.; Jin, Y.; Chi, C.; Han, G.; Jiang, W.; Wang, Z.; Cheng, H.; Zhang, C.; Wang, G.; Sun, C.; et al. Sponge particulates for biomedical applications: Biofunctionalization, multi-drug shielding, and theranostic applications. Biomaterials 2021, 273, 120824.

4. Wibowo, D.; Jorritsma, S.H.T.; Gonzaga, Z.J.; Evert, B.; Chen, S.; Rehm, B.H.A. Polymeric nanoparticle vaccines to combat emerging and pandemic threats. Biomaterials 2021, 268, 120597.

5. Oladapo, B.I.; Ismail, S.O.; Afolalu, T.D.; Olawade, D.B.; Zahedi, M. Review on 3D printing: Fight against COVID-19. Mater. Chem. Phys. 2021, 258, 123943.

6. Reina, G.; Peng, S.; Jacquemin, L.; Andrade, A.F.; Bianco, A. Hard Nanomaterials in Time of Viral Pandemics. ACS Nano 2020, 14, 9364-9388.

7. Donskyi, I.S.; Nie, C.; Ludwig, K.; Trimpert, J.; Ahmed, R.; Quaas, E.; Achazi, K.; Radnik, J.; Adeli, M.; Haag, R.; et al. Graphene Sheets with Defined Dual Functionalities for the Strong SARS-CoV-2 Interactions. Small 2021, 2007091.

8. Hutasoit, N.; Kennedy, B.; Hamilton, S.; Luttick, A.; Rahman Rashid, R.A.; Palanisamy, S. Sars-CoV-2 (COVID-19) inactivation capability of copper-coated touch surface fabricated by cold-spray technology. Manuf. Lett. 2020, $25,93-97$.

9. Serrano-Aroca, Á.; Ferrandis-Montesinos, M.; Wang, R. Antiviral Properties of Alginate-Based Biomaterials: Promising Antiviral Agents against SARS-CoV-2. ACS Appl. Bio Mater. 2021, 4, 5897-5907.

10. Salesa, B.; Llorens-Gámez, M.; Serrano-Aroca, Á. Study of 1D and 2D carbon nanomaterial in alginate films. Nanomaterials 2020, 10, 206.

11. Ahmad Raus, R.; Wan Nawawi, W.M.F.; Nasaruddin, R.R. Alginate and alginate composites for biomedical applications. Asian J. Pharm. Sci. 2021, 16, 280-306.

12. Becker, T.A.; Kipke, D.R.; Brandon, T. Calcium alginate gel: A biocompatible and mechanically stable polymer for endovascular embolization. J. Biomed. Mater. Res. 2001, 54, 76-86.

13. Tai, C.; Bouissil, S.; Gantumur, E.; Carranza, M.S.; Yoshii, A.; Sakai, S.; Pierre, G.; Michaud, P.; Delattre, C. Use of anionic polysaccharides in the development of 3D bioprinting technology. Appl. Sci. 2019, 9. 
14. Gonzalez-Pujana, A.; Orive, G.; Pedraz, J.L.; Santos-Vizcaino, E.; Hernandez, R.M. Alginate Microcapsules for Drug Delivery. In Alginates and Their Biomedical Applications; Springer, Singapore, 2018; pp. 67-100.

15. Lee, K.Y.; Mooney, D.J. Alginate: Properties and biomedical applications. Prog. Polym. Sci. 2012, 37, $106-126$.

16. Venkatesan, J.; Bhatnagar, I.; Manivasagan, P.; Kang, K.H.; Kim, S.K. Alginate composites for bone tissue engineering: A review. Int. J. Biol. Macromol. 2015, 72, 269-281.

17. Zilberman, Y.; Turgeman, G.; Pelled, G.; Xu, N.; Moutsatsos, I.K.; Hortelano, G.; Gazit, D. Polymer-encapsulated engineered adult mesenchymal stem cells secrete exogenously regulated rhBMP-2, and induce osteogenic and angiogenic tissue formation. Polym. Adv. Technol. 2002, 13, 863-870.

18. Biopolymers from Renewable Resources; Kaplan, D.L., Ed.; Springer Berlin Heidelberg: Berlin, Heidelberg, 1998;

19. Yugay, Y.A.; Usoltseva, R. V.; Silant'ev, V.E.; Egorova, A.E.; Karabtsov, A.A.; Kumeiko, V. V.; Ermakova, S.P.; Bulgakov, V.P.; Shkryl, Y.N. Synthesis of bioactive silver nanoparticles using alginate, fucoidan and laminaran from brown algae as a reducing and stabilizing agent. Carbohydr. Polym. 2020, 245, 116547.

20. Akoulina, E.; Dudun, A.; Bonartsev, A.; Bonartseva, G.; Voinova, V. Effect of bacterial alginate on growth of mesenchymal stem cells. Int. J. Polym. Mater. Polym. Biomater. 2019, 68, 115-118.

21. Serrano-Aroca, Á.; Ruiz-Pividal, J.F.; Llorens-Gámez, M. Enhancement of water diffusion and compression performance of crosslinked alginate with a minuscule amount of graphene oxide. Sci. Rep. 2017, 7, 11684.

22. Llorens-Gámez, M.; Salesa, B.; Serrano-Aroca, Á. Physical and biological properties of alginate/carbon nanofibers hydrogel films. Int. J. Biol. Macromol. 2020, 151, 499-507.

23. Grant, G.T.; Morris, E.R.; Rees, D.A.; Smith, P.J.C.; Thom, D. Biological interactions between polysaccharides and divalent cations: The egg-box model. FEBS Lett. 1973, 32, 195-198.

24. Sano, Y. Antiviral activity of alginate against infection by tobacco mosaic virus. Carbohydr. Polym. 1999, 38, $183-186$.

25. Mastromarino, P.; Petruzziello, R.; Macchia, S.; Rieti, S.; Nicoletti, R.; Orsi, N. Antiviral activity of natural and semisynthetic polysaccharides on the early steps of rubella virus infection. J. Antimicrob. Chemother. 1997, 39, 339-345.

26. Gong, Y.; Han, G.T.; Li, X.L.; Wu, Y.; Zhang, Y.M.; Xia, Y.Z.; Yue, C.Q.; Wu, D.W. Cytotoxicity and Antiviral Activity of Calcium Alginate Fibers and Zinc Alginate Fibers. Adv. Mater. Res. 2010, 152-153, 1475-1478.

27. Tran, N.M.; Dufresne, M.; Helle, F.; Hoffmann, T.W.; Francois, C.; Brochot, E.; Paullier, P.; Legallais, C.; Duverlie, G.; Castelain, S. Alginate hydrogel protects encapsulated hepatic $\mathrm{HuH}-7$ cells against hepatitis $\mathrm{C}$ virus and other viral infections. PLoS One 2014, 9, 16-17.

28. Martí, M.; Tunón-Molina, A.; Aachmann, F.L.; Muramoto, Y.; Noda, T.; Takayama, K.; Serrano-Aroca, Á. Protective Face Mask Filter Capable of Inactivating SARS-CoV-2, and Methicillin-Resistant Staphylococcus aureus and Staphylococcus epidermidis. Polymers (Basel). 2021, 13, 207.

29. Prussin, A.J.; Schwake, D.O.; Lin, K.; Gallagher, D.L.; Buttling, L.; Marr, L.C. Survival of the enveloped virus Phi6 in droplets as a function of relative humidity, absolute humidity, and temperature. Appl. Environ. Microbiol. 2018, 84.

30. Farinholt, T.; Doddapaneni, H.; Qin, X.; Menon, V.; Meng, Q.; Metcalf, G.; Chao, H.; Gingras, M.-C.; Farinholt, P.; Agrawal, C.; et al. Transmission event of SARS-CoV-2 Delta variant reveals multiple vaccine breakthrough infections. BMC Med. 2021, 19, 255.

31. Riemersma, K.K.; Grogan, B.E.; Kita-Yarbro, A.; Halfmann, ; Peter; Kocharian, A.; Florek, K.R.; Westergaard, R.; Bateman, A.; Gunnar, ; Jeppson, E.; et al. Shedding of Infectious SARS-CoV-2 Despite Vaccination when the Delta Variant is Prevalent Wisconsin, July 2021. medRxiv 2021, 122, 2021.07.31.21261387.

32. Shitrit, P.; Zuckerman, N.S.; Mor, O.; Gottesman, B.-S.; Chowers, M. Nosocomial outbreak caused by the SARS-CoV-2 Delta variant in a highly vaccinated population, Israel, July 2021. Eurosurveillance 2021, 26, 2100822.

33. Eyre, D.W.; Taylor, D.; Purver, M.; Chapman, D.; Fowler, T.; Pouwels, K.; Walker, A.S.; Peto, T.E.A. The impact of SARS- 
CoV-2 vaccination on Alpha and Delta variant transmission. medRxiv 2021, 2021.09.28.21264260.

34. Frígols, B.; Martí, M.; Salesa, B.; Hernández-Oliver, C.; Aarstad, O.; Ulset, A.-S.T.; Sætrom, G.I.; Aachmann, F.L.; SerranoAroca, Á. Graphene oxide in zinc alginate films: Antibacterial activity, cytotoxicity, zinc release, water sorption/diffusion, wettability and opacity. PLoS One 2019, 14.

35. Kropinski, A.M.; Mazzocco, A.; Waddell, T.E.; Lingohr, E.; Johnson, R.P. Enumeration of bacteriophages by double agar overlay plaque assay. Methods Mol. Biol. 2009, 501, 69-76.

36. Total RNA Purification Kit Product Insert.

37. Pietropaolo, V.; Seganti, L.; Marchetti, M.; Sinibaldi, L.; Orsi, N.; Nicoletti, R. Effect of natural and semisynthetic polymers on rabies virus infection in CER cells. Res. Virol. 1993, 144, 151-158.

38. Pardee, K.I.; Ellis, P.; Bouthillier, M.; Towers, G.H.N.; French, C.J. Plant virus inhibitors from marine algae. Can. J. Bot. 2004, 82, 304-309.

39. Sinha, S.; Astani, A.; Ghosh, T.; Schnitzler, P.; Ray, B. Polysaccharides from Sargassum tenerrimum: Structural features, chemical modification and anti-viral activity. Phytochemistry 2010, 71, 235-242.

40. Astani, A.; Reichling, J.; Schnitzler, P. Comparative Study on the Antiviral Activity of Selected Monoterpenes Derived from Essential Oils. Phyther. Res. 2008, 22, 544-549.

41. Schnitzler, P.; Schneider, S.; Stintzing, F.C.; Carle, R.; Reichling, J. Efficacy of an aqueous Pelargonium sidoides extract against herpesvirus. Phytomedicine 2008, 15, 1108-1116.

42. Sanmartín-Santos, I.; Gandía-Llop, S.; Salesa, B.; Martí, M.; Lillelund Aachmann, F.; Serrano-Aroca, Á. Enhancement of Antimicrobial Activity of Alginate Films with a Low Amount of Carbon Nanofibers (0.1\% w/w). Appl. Sci. 2021, $11,2311$. 